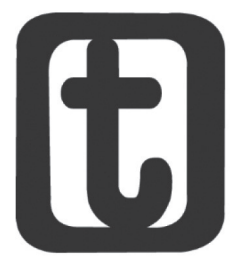

\title{
OS PROJETOS DE ASSISTÊNCIA SOCIAL EM DISPUTA E O PADRÃO HÍBRIDO DE GESTÃO DO SUA' ${ }^{1}$
}

\author{
The projects of social assistance in dispute and the hybrid standard \\ of management of SUAS
}

Robson Roberto Silva*

(cc) BY-NC

\section{RESUMO}

Este trabalho busca, por meio de uma pesquisa bibliográfica e documental, analisar a construção da política pública de assistência social no Brasil, considerando os distintos projetos em disputa nessa área. Assim, procura demonstrar que -, como resultado do projeto neoliberal hegemônico de assistência social, que conserva aspectos de um projeto tradicional, e que colide e convive com um projeto que concebe a assistência como direito social e dever do Estado -, vem sendo construído desde o meado da década de 1990 um padrão híbrido de gestão, cujos principais traços de continuidade e rupturas são apresentados neste trabalho no período de construção do Sistema Único de Assistência Social (SUAS).

\section{PALAVRAS-CHAVE}

Política de assistência social. Projetos em disputa. Gestão social. SUAS. Brasil.

ABSTRACT

This work seeks, through a bibliographical and documentary research, to analyze the construction of the public policy of social assistance in Brazil, considering the different projects in disputes in this area. Thus, it seeks to demonstrate that - as a

1 Este trabalho é parte das reflexões apresentadas na tese de doutorado construída no âmbito do Programa de Pós-graduação em Serviço Social da Universidade Federal do Rio de Janeiro (UFRJ) e inclui algumas discussões sobre a condução da política nacional de assistência social na conjuntura atual.

* Assistente Social. Doutorado em Serviço Social. Professor Adjunto da Escola de Serviço Social da Universidade Federal Fluminense (UFF, Niterói, Brasil). Rua Miguel de Frias, 9, Icaraí, Niterói, RJ, CEP.: 24220-900. E-mail: <robson.essuff@gmail.com>. 
result of the neoliberal hegemonic social assistance project that preserves aspects of a traditional project that collides with and coexists with a project that conceives assistance as a social right and the duty of the State - The mid-1990s a hybrid management pattern, whose main traits of continuity and disruption are presented during the construction period of the Unified Social Assistance System (SUAS).

\section{KEYWORDS}

Social assistance policy. Projects in dispute. Social management. SUAS. Brazil..

Submetido em: 6/9/2017

Aceito em: 14/11/2017.

\section{INTRODUÇÃO}

Ao menos no Serviço Social, a produção de conhecimento científico vem destacando as disputas de projetos/propostas/posições distintas de seguridade social (IAMAMOTO, 2009; BEHRING; BOSCHETTI, 2006; MOTA, 2000), de política de saúde (BRAVO, 2001), de previdência (TEIXEIRA, 2006) e de assistência social (SILVA, 2014). Nessa literatura, é consenso que as políticas sociais públicas surgem como respostas às expressões da "questão social", que se agravam no contexto mundial do capitalismo monopolista; e que tais respostas são uma das mediações voltadas para a reprodução material da força de trabalho e do conjunto da sociedade.

Por serem resultantes de um complexo jogo político atravessado por contradições, conflitos, acordos e concessões entre os sujeitos (representantes da burguesia, dos trabalhadores e de setores da burocracia estatal que têm um compromisso com uma dessas classes sociais), o processo de formulação e de execução/ implementação dessas políticas sociais (que levam em conta as diversas estruturas e as divisões no aparelho do Estado) podem tornar essas medidas distantes das reais necessidades da classe trabalhadora e de suas frações. Porém, dependendo do grau de mobilização e organização do conjunto dos trabalhadores, essas políticas sociais, quando articuladas a uma política econômica e financeira que não a restrinjam significativamente, podem "[...] assinalar conquistas parciais, [...] importantes no largo trajeto histórico que supõe a ruptura dos quadros da sociedade burguesa" (NETTO, 2001, p. 34).

No Brasil, as políticas sociais nascem e deenvolvem-se a partir dos anos 1930 em um contexto marcado pela ampliação e redefinação 
do papel do Estado no processo produtivo e na regulação da reproduação social, sobretudo como respostas às reivindicações da classe operária. Nesse período as políticas sociais são criadas seguindo a lógica do seguro social ou bismarckiana; e a assistencia social não tinha o status de política pública. A Constituição Federal de 1988, que expressa às contradições e tensões de uma sociedade dividida em grupos e classes sociais, alterou legalmente esse padrão de proteção social, tendo em vista que, ao incluir a política de saúde, de previdência e de assistência social, como pilares da seguridade social, estabeleceu um formato de proteção social mais abrangente, inclusivo e com uma orientação democrática e redistributiva. Particularmente, a saúde passou a ser concebida como uma política universal, a previdência social permaneceu seguindo a lógica da contribuição e a assistência social passou a ser reconhecida como uma política pública para quem dela necessitar.

As leis orgânicas, as constituições estaduais, municipais etc. promulgadas em consonância com esta Carta Magna, estabeleceram, assim, que a gestão pública das políticas de saúde, assistência social, educação, dentre outras, fosse orientada pelas diretrizes constitucionais da descentralização políticoadministrativa e da participação da população na elaboração e controle das ações intergovernamentais. Em razão dessas exigências quanto à organização das políticas sociais em todo território brasileiro, tornou-se frequente na literatura o uso de expressões, como gestão social, gestão pública democrática, descentralizada e/ou participativa. Particularmente, o termo gestão social passou a ser empregado para designar as atividades desenvolvidas pelo Estado no âmbito das políticas sociais, como os processos de formulação e implementação, como também as práticas realizadas por determinadas organizações da sociedade civil.

Entretanto, as transformações contemporâneas do modo de produção capitalista, que trazem consequências para a correlação de forças e requisitam "novas" formas de gestão pública e de reorganização do Estado, colocam há necessidade de aprofundar o debate acerca das contradições no âmbito da gestão das políticas sociais, considerando as estruturas pré-existentes e as tensões 
entre os projetos coletivos distintos, que, vinculados a projetos de sociedade antagônicos e em disputa², imprimem padrões híbridos de gestão, com traços mais ou menos conservadores ou progressistas, a depender da conjuntura e da correlação de forças entre os sujeitos, que defendem concepções distintas de seguridade social, de política/gestão social e de sociedade.

Neste sentido, este trabalho torna-se relevante por procurar demonstrar -, nos marcos do processo de redemocratização da sociedade brasileira e do período de neoliberalização ${ }^{3}$ que tem início nos anos 1990 -, as contradições da política de assistência social e do seu padrão de gestão, à luz dos projetos coletivos em disputa nessa área social. Particularmente, por buscar apresentar algumas das principais contradições da gestão do Sistema Único de Assistência Social (SUAS), partindo da premissa que a gestão da política pública de assistência social ergue-se numa estrutura administrativa patrimonial-burocrática, que, ao ser tencionada, incorpora traços de um padrão de gestão pública democrática e, sobretudo, do chamado gerencialismo puro: uma concepção de gestão/administração pública criada a partir da influência das administrações no setor privado, que em termos prático não rechaça o patrimonialismo e que os ideólogos do neoliberalismo defendem como um "modelo" ideal de gestão.

Alguns autores vêm apresentando reflexões que contribuem com essa argumentação. Bento (2003) destaca que nem todos os países adotaram os mesmos padrões de gestão e/ou todos os dispositivos previstos em cada um deles. Portanto, não se pode falar de um "modelo" unitário. lasi (2012), por sua vez, considera que "[...] não (se pode) afirmar que o padrão do gerencialismo puro supera, no sentido restrito da palavra, a organização racional burocrática em suas formas mais marcantes" (IASI, 2012, p. 57). Nessa direção, Souza Filho (2011) aponta que o gerencialismo não supera, como

\footnotetext{
2 Segundo Netto (2006, p. 142), "[...] os membros da sociedade, homens e mulheres, sempre atuam teleologicamente - isto é: a ação humana, seja individual, seja coletiva, tendo em sua base necessidades e interesses, implica sempre um projeto que, em poucas palavras, é uma antecipação ideal da finalidade que se pretende alcançar, com a invocação dos valores que a legitimam e a escolha dos meios para lográ-la".

3 De acordo com Harvey (2008, p. 80), "[...] a dinâmica evolutiva da neoliberalização tem agido de modo a forçar adaptações que variam muito de lugar para lugar e de época para época [...]", notando-se também desvios do modelo da teoria neoliberal.
} 
também repõe o patrimonialismo sobre bases racional-legais, e limita a construção de uma gestão pública democrática como uma das mediações para superar a ordem do capital.

As reflexões desses autores acabam também reforçando quanto à importância da utilização de um método de pesquisa que auxilie a desvendar a realidade como um todo complexo, múltiplo, contraditório, em devir, ou seja, como uma totalidade. Por essa razão, este trabalho utilizou o método dialético como forma de compreender a realidade da aparência para a essência; e a pesquisa bibliográfica e documental, como instrumentos que permitiram identificar e coletar informações importantes sobre a construção da política de assistência social e de seu sistema decentralizado e participativo (hoje denominado de SUAS) entre os anos 1980 e $2016^{4}$.

Assim, o trabalho procurou apresentar, na primeira seção, uma análise a respeito da construção dessa política social, considerando os diferentes projetos em disputa nessa área; e particularmente demonstrar que-, em decorrência da hegemonia do projeto neoliberal de assistência social que conserva aspectos de um projeto tradicional, e que colide e convive com um projeto que concebe a assistência como direito social e dever do Estado -, vem sendo construído desde a segunda metade da década de 1990 um padrão híbrido de gestão, cujos traços de continuidade e rupturas são apresentados na segunda seção deste trabalho, que trata da gestão do SUAS.

\section{A CONSTRUÇÃO DA POLÍTICA DE ASSISTÊNCIA SOCIAL A PARTIR}

\footnotetext{
4 Foram utilizadas como fonte de pesquisa bibliográfica: "Aguiar (s/d), Behring (2008), Boschetti (1993; 2003; 2005; 2006), Coelho (2013), Couto et al (2010), Draibe e Aureliano (1989), Fleury (1999), Gomes (1999), Menezes (1998), Mestriner (2008), Montaño (2005), Mota (2008), Muniz (2006), Paiva (1993), Pastorini (2002; 2010), Paz (1996), Pereira (1995; 2010), Soares (2001), Sposati (1991; 1997; 2005), Sposati e Falcão (1990), Tatiana Dahmer Pereira (2009), Telles (1998), Yazbek (2005; 2006) e Yazbek et al (2010). Além desses autores, cabe mencionar o artigo de Stein (1999), (Raichelis (2010), Araújo et al (2010)]; e também os documentos institucionais e as legislações, como leis, pré-projetos de leis, decretos, medidas provisórias e portarias sobre a assistência social, o chamado "terceiro setor" e as "reformas" do Estado; políticas, resoluções e normas operacionais da assistência social; cadernos de textos, relatórios, anais das conferências e atas das reuniões realizadas entre 1996 e 2010 pelo conselho dessa área social, ambos de abrangência nacional; relatórios de pesquisas do Instituto de Pesquisa Econômica Aplicada e do Instituto Brasileiro de Geografia e Estatística; cadernos, manuais e relatórios de investigações publicados pelos ministérios responsáveis pela assistência social; revistas e parâmetros de organizações da sociedade civil que tratam dessa política social" (SILVA, 2014, p. 23-24).
} 


\section{DOS PROJETOS EM DISPUTA}

A construção da assistência como política pública tem sido resultado das tensões entre projetos distintos nessa área social, alinhados a projetos antagônicos de sociedade desde o início da chamada "Nova República”. De acordo com Coutinho (2008), há uma proposta liberalcorporativa, que representa os interesses das classes dominantes e que, além de manter o velho estilo de se fazer política, mas a partir de novas formas, defende o predomínio do privado sobre o público; e uma proposta democrática alternativa (denominada também de democracia de massa ou de democratização), que representa os interesses das classes subalternas e que está centrada na reconstrução/ redefinição dos espaços públicos em todas as esferas da sociedade.

Por entender que esses “[...] projetos societários estão presentes na dinâmica de qualquer projeto coletivo [...]" (TEIXEIRA; BRAZ, 2009, p. 5) e que tais projetos desenvolvem-se em meio às contradições que são desencadeadas pelas relações entre as classes sociais antagônicas, pode-se apontar que ligado ao projeto liberal-corporativo está o projeto tradicional de assistência social. Este é defendido por setores do governo e da sociedade civil, que representam os interesses de grupos e classes dominantes. Neste projeto conservador:

- a concepção de assistência vincula-se ao atendimento de indivíduos, grupos e comunidades pobres, cujas necessidades sociais são compreendidas como morais, psicológicas ou como incapacidades individuais; a pobreza é concebida em termos absolutos e os programas e ações são considerados como ajuda/ caridade ou benemerência.

- a gestão nessa área segue os padrões tradicionais, caracterizados pela centralização; fragmentação institucional; burocratização, imediatismo, improvisações e descoordenação das ações; exclusão dos usuários dos processos decisórios; e por uma racionalidade que combina um conjunto de práticas antidemocráticas (paternalistas, autoritárias, corporativistas, clientelistas, patrimonialistas etc.) e o primeiro damismo.

- a descentralização é compreendida como desconcentração associada à delegação e/ou à desresponsabilização. 
- e a parceria com as instituições de caridade e filantrópicas é vista como uma forma de ampliar a participação do setor privado, alimentar as engrenagem do sistema clientelista, o corporativismo e privatizar o público.

Por sua vez, nota-se que articulado ao projeto de democratização vem sendo construído o projeto de assistência como direito social e dever do Estado. Este projeto tem sido defendido por setores da burocracia estatal e da sociedade civil, que representam e lutam pelos interesses dos grupos e classes subalternas. Neste projeto progressista:

- a concepção de assistência está associada ao atendimento das necessidades sociais, cuja raiz é resultado das contradições inerentes ao modo de produção capitalista; e os projetos, programas, serviços e benefícios são elaborados e implementados pautados na concepção de uma política de seguridade social que materialize direitos a maioria dos trabalhadores.

- a proposta de gestão pauta-se numa perspectiva pública e democrática; inclui a construção de um sistema de assistência social, que considere as diretrizes da descentralização e da participação da população na formulação e controle dessa política social, a cooperação intergovernamental, a intersetorialidade, a contratação através de concurso público, que contemple plano de carreiras e salários e que garanta direitos trabalhistas.

- a descentralização é compreendida como uma estratégia para obter a redistribuição do poder entre as esferas de governo e entre Estado e organizações e espaços públicos da sociedade civil.

- e o Estado é visto como o principal responsável pela assistência social como política de seguridade social, que deve ser direcionada a todos que necessitarem independente da capacidade contributiva.

A disputa entre esses dois projetos antagônicos de assistência social deve ser compreendida considerando as transformações econômicas, políticas e sociais, que estão relacionadas com a inserção subalterna do Brasil no sistema capitalista mundial. A crise estrutural do capital eclodida nos anos 1970 forjou no país um amplo e heterogêneo movimento social e político, que exigia transformações da sociedade e um "novo" papel do Estado. Nesse contexto-marcado por crise econômica e política, pelo processo de 
redemocratização, pela implementação de planos de estabilização da economia, que não conseguiram combater a inflação, diminuir a dívida pública, restringir o aumento do desemprego/do trabalho informal e reduzir à insatisfação da população -, a disputa entre o projeto conservador e o progressista se expressou:

- Nos primeiros documentos nacionais que apresentavam as contradições da assistência social. A exemplo, o Primeiro Plano Nacional de Desenvolvimento da Nova República (1985), por um lado, indicava a articulação intergovernamental, a descentralização com forte tendência a municipalização e a participação dos usuários em diferentes níveis do processo de decisão e implementação das ações sociais, mas, por outro, sugeria ao governo federal a focalização das ações em segmentos da população, restringia suas iniciativas que visasse a complementar as atividades estaduais e municipais, como também incentivava a criação de associações comunitárias e o apoio familiar (FLEURY, 1999; BOSCHETTI, 2006).

- No processo de inclusão na agenda da Assembleia Nacional Constituinte de 1987, sobretudo entre os sujeitos progressistas, que, no âmbito da Comissão de Ordem Social, construíram o documento "Assistência social: argumentos para inclusão no texto constitucional", que apresentava uma concepção de assistência social, de gestão (que incluía a criação de um sistema único de assistência social) e de descentralização, coerente com o projeto que concebe essa política social como direito e dever do Estado. Entretanto, neste processo os sujeitos conservadores que compunham o chamado "Centrão" defendiam a assistência social como uma área de responsabilidade não apenas do Estado, mas de toda a sociedade, a restrição das ações somente aqueles em situação de pobreza absoluta, a redução da cobertura dos benefícios e do valor das transferências diretas de renda e a supressão dos dispositivos referentes à descentralização e à participação da população na formulação e controle dessa política social (BOSCHETTI, 2006).

- No texto da Constituição Federal de 1988, que incluiu a seguridade social como um sistema de proteção social composto pelas políticas de saúde, previdência e assistência social. Nesse sistema, as ações de assistência social devem ser organizadas seguindo as diretrizes 
da descentralização e da participação da população na formulação da política e no controle das ações em todos os níveis, cabendo ao governo federal à coordenação e à normatização gerais e aos governos estaduais e municipais a coordenação e a execução dos seus respectivos programas, bem como às entidades beneficentes e de assistência social. Porém, esta Constituição, ao estabelecer essas funções também às entidades, nos termos de Boschetti (2006, p. 176), “[...] ]obscureceu a distinção entre ações públicas e filantrópicas e fortaleceu uma perspectiva de assistência social como 'caridade' privada. Tal novidade foi resultado do lobby das associações filantrópicas”.

- Na reorganização da assistência social no governo Sarney (1985-1990), que não buscou adequar à assistência social aos novos dispositivos constitucionais; pelo contrário, manteve as características tradicionais de gestão dessa área social, que continuou sendo utilizada para exercer as práticas assistencialistas, clientelistas e autoritárias.

- No processo de discussão e formulação do projeto de Lei Orgânica da Assistência Social (LOAS), que iniciou após a promulgação da Constituição de 1988. Destaca-se aqui, com base em Boschetti (2006), a participação de representantes da Secretaria de Assistência Social do Ministério da Previdência e Assistência Social, que exibiriam um pré-projeto, que -, diferente da proposta progressista construída pela equipe composta por professores e especialistas da Universidade de Brasília e do Instituto de Pesquisa Econômica Aplicada (UNB/IPEA) -, restringia/limitava a assistência no âmbito da seguridade, como uma maneira de evitar a utilização dos recursos da previdência social; e o pré-projeto apresentado pela associação que representava nacionalmente os servidores da Legião Brasileira de Assistência (LBA): a chamada ANASSELBA, que incorporou quase por completo as formulações contidas no préprojeto da UNB/IPEA, a exceção do aspecto referente à organização e gestão, como normatização, coordenação e controle das ações no âmbito intergovernamental, que no seu pré-projeto era de responsabilidade desta instituição.

Entretanto, o governo Sarney não enviou ao parlamento nenhum projeto de lei de regulamentação das políticas de seguridade 
social, coube ao presidente da Comissão de Saúde, Previdência e Assistência Social da Câmara dos Deputados encaminhá-los. Na área da assistência, apresentou o Projeto de Lei (PL) n³.099/1989, do deputado Raimundo Bezerra, que era muito semelhante ao préprojeto de lei da UNB/IPEA. Após a aprovação do PL nessa Comissão (que não incluiu muitas das emendas dos sujeitos progressistas), o documento foi encaminhado a Comissão de Finanças e Tributação, mas o recesso interrompeu os trabalhos, sendo retomado após a posse do presidente da República Fernando Collor de Mello (1990-1992).

Este presidente não só abriu espaços para a incorporação do ideário neoliberal difundido no mundo capitalista, como também deu continuidade à forma tradicional de se fazer política no país. Segundo Fernandes (1990, p. 33), "Collor alimentou a perpetuação do mandonismo, do paternalismo, do clientelismo e de todas as suas sequelas e condições". Em seu governo permaneceu a disputa entre os sujeitos que lutavam pela efetivação do projeto de assistência como direito social e dever do Estado e aqueles que defendiam a manutenção do projeto tradicional. Destaca-se nesse cenário:

- O "Projeto de Reconstrução Nacional” do presidente Collor (2008), que definiu a assistência social como uma área complementar e emergencial, que seria destinada a pessoas, famílias e grupos populacionais (em especial o materno-infantil) sem condições de automanutenção; e que reduziu as necessidades e desigualdades sociais a problemas de ordem individual, que se expressam com particularidades no âmbito local e a descentralização à desconcentração ou a transferência de responsabilidade.

- Os documentos elaborados pelos órgãos federais, como o Plano de Promoção e Assistência Social criado pelo Ministério da Ação Social (MAS), o Plano Plurianual de Metas da LBA - 1990/1995 e o Plano Diretor da LBA Triênio 1991/1993 (BOSCHETTI, 1993), que demonstravam a intenção de manter a tradicional organização e gestão da assistência social.

- O veto do projeto de lei que regulamentaria a assistência social pelo presidente Collor, que assim ignorou a assistência como direito social previsto constitucionalmente; reforçou a tese liberal de que o mercado é a principal esfera para melhorar a condição 
humana e até mesmo sobrepor às leis sociais; manteve a ideia de assistência social como ajuda pública, que deve ser prestada não exclusivamente pelo Estado, mas por toda a sociedade; permitiu que a assistência social continuasse sendo um recurso fundamental das relações marcadas pela prática de favor, clientela, tutela e privatização do público; e não menos importante, recusou a descentralização, pois essa diretriz eliminaria a permanência da centralização no âmbito do governo federal (SPOSATI, 1991; BOSCHETTI, 1993, 2006; SOARES, 2001).

- A implementação das ações de assistência social pelo MAS, que manteve a fragmentação e descoordenação da área social e continuou sendo um espaço propício para corrupção, clientelismo e promoção da benemerência. A exemplo, o Conselho Nacional de Serviço Social, que havia sido transferido do Ministério da Educação para o MAS, permaneceu emitindo, sem qualquer critério técnico, certificados de filantropia às instituições desse gênero e outras com fins lucrativos. Não muito diferente, a LBA, sob a gestão da primeira dama Rosane Collor, continuou transferindo recursos financeiros a instituições filantrópicas, dentre elas, uma instituição fictícia, administrada por membros da sua família, no estado de Alagoas.

- A realização de seminários e a produção e publicação de documentos, que denunciavam a forma tradicional de compreender e organizar a assistência social no Brasil. A "Declaração do Rio de Janeiro" publicada em dezembro de 1990, por exemplo, apresentava críticas com relação a essa organização político-administrativa, como também propostas de criação de um sistema único, que foram construídas pelos representantes dos governos subnacionais (com alguma experiência nessa área) no "I Seminário Nacional de Estados e Municípios sobre Políticas Sociais", realizado no Rio de Janeiro (RJ).

As constantes denúncias de corrupção e a má administração do governo Collor levaram o Congresso Nacional a abrir uma Comissão Parlamentar de Inquérito, que resultou no impeachment desse presidente em setembro de 1992. Segundo Antunes (2005), o processo de impeachment só foi concluído quando, além da pressão do movimento popular, o vice-presidente Itamar Franco, pressionado por setores dominantes, aceitou assumir a direção do país. Seu 
governo (1992-1994) herdou uma crise com dimensões éticas, políticas, econômicas e sociais, como também foi marcado por profundas ambiguidades. De acordo com Boschetti (2006), a conjuntura era um pouco mais favorável e permitiu a retomada do processo de criação do projeto da LOAS, que contou com a participação de diferenças forças sociais. Destaca-se aqui a participação da ANASSELBA, que descontente com a má administração da LBA pela primeira dama, passou a defender a descentralização como um dispositivo constitucional conforme previa o pré-projeto de lei da UNB/IPEA e a integrar a "Comissão Nacional pela Lei Orgânica da Assistência Social" -, constituída também pelas entidades da sociedade civil, como o Conselho Federal de Serviço Social, a Associação Nacional de Assistentes Sociais, a Central Única dos Trabalhadores (CUT), o Núcleo de Estudos e Pesquisas em Política Social da UNB (NEPPOS/ UNB), a Associação Brasileira de Ensino e Pesquisa em Serviço Social e a Pontifícia Universidade Católica de São Paulo (PUC-SP) -, que aprimorou o primeiro projeto de lei elaborado pelo grupo da UNB/IPEA.

No parlamento, quando chegou a ser encaminhado já havia sido enviado outros projetos, que em comparação a este eram mais restritos. Na Câmara, a hipertrofia do Executivo se fazia perceber na postura dos deputados conservadores que buscavam aprovar um projeto de lei que não aumentasse o gasto social. A relatora designada pela Comissão de Seguridade Social e Família tratou de redigir um projeto que conciliava interesses distintos. Se por um lado, rejeitou as emendas que ampliavam os benefícios de prestação continuada e as que previam a extinção das instituições federais com a transferência dos servidores e do patrimônio para os governos subnacionais; por outro, incorporou a emenda que fazia referência à primazia do Estado na condução da política de assistência social, a que estabelecia mais detalhadamente as atribuições das três diferentes esferas governamentais; e a que atribuía ao conselho de assistência social a função de analisar e aprovar o orçamento dessa política social. Após o término da sua redação, os deputados desta Comissão chegaram à conclusão de que era melhor aprovar o projeto de lei do que persistir nas mudanças e correr o risco de ser vetado (BOSCHETTI, 2006).

No Senado o projeto de lei não sofreu nenhuma modificação e em seguida foi encaminhado ao presidente Itamar, que sancionou a Lei 
Orgânica da Assistência Social (LOAS), n 8.742, em dezembro de 1993 (BRASIL, 1993). A principal inovação desta Lei está relacionada à reorganização da assistência como direito social por meio de um sistema descentralizado e participativo. Este sistema deve reger suas ações com base em dois eixos que se articulam: o primeiro compreende as relações entre os governos federal, estaduais e municipais; e o segundo as relações entre Estado e sociedade civil. Neste último existem duas dimensões a destacar: i) a primazia do Estado e a participação das entidades de assistência social, que devem prestar suas ações na perspectiva dos direitos; e ii) a participação social na elaboração e controle das ações de assistência social, por meio de espaços vinculados a órgãos das administrações públicas, como os conselhos, que são instâncias deliberativas, de caráter permanente e composição paritária entre representantes do governo e da sociedade civil eleitos em fórum próprio.

Entretanto, a maior preocupação do governo Itamar foi a de implantar o Plano Real, que seguia o programa de estabilização proposto pelo Fundo Monetário Internacional (FMI) e as "reformas" neoliberais recomendadas pelo Banco Mundial. Dessa forma, preferiu direcionar seus esforços na execução do Plano de Combate à Fome e à Miséria pela Vida (1993), que reforçou a forma tradicional de conceber, organizar e gerenciar a assistência social, limitando-se apenas a promulgar a LOAS e a institucionalizar o Conselho Nacional de Assistência Social (CNAS).

Fernando Henrique Cardoso - FHC (1995-2002), desde que assumiu a presidência da República procurou consolidar o projeto liberal-corporativo pela via da ortodoxia neoliberal. No mesmo dia que tomou posse publicou a Medida Provisória (MP) $n^{\circ} 813$, de 01/01/1995, que dispõe sobre a organização da presidência da República e dos ministérios, inaugurando assim uma das marcas da sua gestão: a imposição da contrarreforma5, cujas principais proposições de administração/gestão pública foram e são inspiradas no gerencialismo, particularmente na concepção do Decreto-lei $n^{\circ}$ 200, de 25 de fevereiro de 1967 (BRASIL, 1967) e dos organismos multilaterais, como o Banco

5 Segundo Coutinho (2008), Gramsci ao tratar da contrarreforma "[...] admite que até mesmo neste caso tem lugar uma "combinação entre o velho e o novo" (COUTINHO, 2008, p. 98). 
Mundial. Tais proposições foram condensadas no Plano Diretor da Reforma do Aparelho do Estado conduzido pelo Ministério da Administração Federal e Reforma do Estado (MARE), mas não superaram as formas mais marcantes do padrão burocráticopatrimonialista.

No âmbito dessa proposta contrarreformista vem sendo construído até os dias atuais o projeto neoliberal hegemônico de assistência social, que se traduz em um mix de conservadorismo e “modernização neoliberal”. . Neste projeto (neo)conservador:

- a concepção de assistência vincula-se ao atendimento a indivíduos, famílias e comunidades pobres e extremamente pobres, não sendo uma área de definição de política social, mas sim de improvisações de ações e implementação de programas seletivos e focalizados, que concebem a pobreza em termos absoluto e que adotam como principais eixos de intervenção a transferência de renda condicionada, o empreendedorismo e a solidariedade.

- a proposta de gestão pauta-se no padrão gerencialista, caracterizado pela centralização do poder de decisão na União, separação entre órgãos formuladores e implementadores, "descentralização", conselhos consultivos/espaços de interlocução, terceirização, desregulamentação da força de trabalho, avaliação por desempenho, produtividade, criação de sistemas de informação, e valorização do saber burocrático.

- a descentralização é compreendida como desconcentração, delegação e privatização.

- o Estado é visto como um parceiro das instituições/organizações da sociedade civil (famílias, comunidades, associações voluntárias, organizações não governamentais etc.), que amplia a legislação e repassa recursos financeiros não no mesmo grau de transferência de responsabilidade, o que pode assim expressar privatização e/ou refilantropização do atendimento.

Em razão desse projeto neoliberal hegemônico de assistência social, que colide e convive com o projeto que concebe a assistência 
como direito social e dever do Estado, nota-se a constituição de um padrão híbrido de gestão, tendo em vista o esforço, por um lado, dos representantes de grupos e classes subalternas de efetivar a LOAS e de criar e implantar instrumentos (normas operacionais, política nacional, resoluções etc.) importantes para alçar a assistência social à condição de política pública; e por outro, dos representantes de grupos e classes dominantes de dar continuidade as práticas (neo)conservadoras através da elaboração e utilização de medidas contrarreformistas, como a MP $n^{\circ}$ 813. Segundo Pereira (1995), para estes sujeitos:

[...] a assistência social não é área de definição política [...] É área de engenhosidade operativa, de campanhas, de apelos carismáticos, de mobilizações espetaculares de curto prazo [...]. Daí o fracionamento, na MP, do seu campo de atuação, a justaposição de programas dirigidos à calamidade da fome e da pobreza absoluta e a tendência em transformá-la em ação "focalizada" e desagarrada de um projeto nacional de desenvolvimento sócioeconômico (PEREIRA, 1995, p. 149).

Por meio desta MP, o governo FHC com apoio de setores conservadores da sociedade civil extinguiu ministérios, centros, instituições, como a LBA, criou o Ministério da Previdência e Assistência Social (MPAS), que passou contar com a Secretaria de Assistência Social (SAS) e redistribuiu as ações da área em vários ministérios. Paralelamente, com a MP criou-se o Programa Comunidade Solidária (PCS), composto por um Conselho de caráter consultivo (presidido pela primeira dama Ruth Cardoso) vinculado à Casa Civil da presidência da República, que não seguia as prescrições legais que tratam da seguridade social e da assistência como direito, tendo em vista que tal Programa buscava incentivar a parceria e a articulação entre os órgãos públicos federais, os três níveis de governo e a sociedade no "combate" à pobreza absoluta. De acordo com Pastorini (2002), o PCS tinha como eixo central:

[...] a ideia da parceria entre os três níveis do governo (federal, estadual e municipal) e a sociedade civil, na busca de articulação e coordenação de ações no alívio à pobreza e à fome. Por isso [...] uma estratégia que busca potencializar os resultados através da 


\section{tempOrolis sıva, robson.}

integração e convergência das ações tanto do governo quanto da sociedade, já que ninguém poderia hoje atuar sozinho para atender à pobreza. Pelo contrário, seria necessário o somatório de esforços guiados pelo princípio da solidariedade, entendido como engajamento ético de quem está preocupado com a situação de fome e miséria no país (PASTORINI, 2002, p. 230).

Assim, a assistência social continuou sendo prestada por diferentes órgãos. Portanto, sem comando único como prevê a LOAS, não se tinha garantias de que a cultura tradicionalista presente nas institucionais governamentais e também em muitas das organizações da sociedade civil pudesse ser confrontada e alterada pela cultura do direito à assistência social. Na maioria dos governos estaduais e municipais essa situação era mais grave, a assistência social ainda era vista como um assunto que não exigia conhecimento especializado, qualquer órgão ou departamento poderia praticá-la, mesmo com o esforço dos sujeitos progressistas referentes à criação/construção dos conselhos, fundos, planos e fóruns nessa área social. A SAS do MPAS chegou a criar os Escritórios Regionais de Assistência Social (ERSAS), alegando manter um grupo de técnicos do governo nacional capacitados para assessorarem as secretarias dos estados e municípios no processo de construção de um sistema descentralizado e participativo. Porém, essa iniciativa significou muito mais uma maneira efetiva de desconcentrar e responsabilizar os municípios e os estados pelas ações de assistência social, como se pode notar em uma das atas de reunião ordinária do CNAS:

[...] Não existe descentralização nenhuma. O que existe é uma falta de respeito em relação às parcerias. $\mathrm{E}$ a postura adotada pela SAS em relação aos parceiros não é adequada na visão dos Estados. Está muito claro isso para nós e é unânime. Os Estados ficaram com muito ônus e pouco poder de mobilidade, de autonomia no que dizia respeito à esfera estadual. (CONSELHO NACIONAL ASSISTÊNCIA SOCIAL, 1997, p. 38).

Posterirormente, com a ampliação dos mecanismos de ajuste estrutural, o governo $\mathrm{FHC}$, em seu segundo mandato, extinguiu os ERSAS, ampliou a delegação de funções de gestão aos estados 
e aos municípios, sem repassar no mesmo grau recursos e poder de decisão. Assim, desrespeitou as diretrizes da LOAS, que prevê como mencionado o comando único da política em cada esfera de governo; estabeleceu normas, padrões e critérios sobre a execução de projetos, programas e serviços nacionais, sem levar em consideração a heterogeneidade dos estados e municípios; incentivou a produção, a avaliação por desempenho, o voluntariado e a contratação por meio de terceirizações e do uso de Recibo de Profissional Autônomo (RPA), que acabaram em alguma medida repondo o patrimonialismo e alimentando a engrenagem do sistema clientelista; além disso, ampliou a legislação e os incentivos financeiros às organizações da sociedade civil, que a razão instrumental denomina de "terceiro setor".

Apesar do Partido dos Trabalhadores(PT), no processo constituinte de 1987 e nas campanhas eleitorais, ter defendido a incorporação e ampliação das políticas sociais, a construção dos direitos de cidadania e a democratização, Luiz Inácio Lula da Silva (2003-2010) e a presidente também eleita pelo PT, Dilma Rousseff (2011-2016), compuseram seus governos com uma ampla política de coalizão de classes; criaram estratégias intergovernamentais; e cooptaram determinadas instituições e organizações políticas, que entre os anos 1970 e 1980 dedicaram-se a construir uma contra hegemonia, como os sindicatos, a CUT, o próprio PT, que assumiram cargos de direção nos conselhos dos fundos de pensão, em empresas estatais, órgãos federais etc. Assim, desmobilizou frações da classe trabalhadora e dos movimentos sociais com a renovação do corporativismo e do patrimonialismo. Em outras palavras, tratou de impedir o processo de construção de um projeto de democratização, pois "[...] desarmou as resistências ao modelo liberal-corporativo e abriu assim caminho para uma maior e mais estável consolidação da hegemonia neoliberal" (COUTINHO, 2008, p. 141).

Embora Lula tenha incluído no seu "Programa de Governo 2002" a criação do sistema descentralizado e participativo para a política de assistência social -, que esteve pautado na agenda da Constituinte de 1987, no processo de regulamentação dessa política e nas conferências nacionais dessa área nos governos $\mathrm{FHC}$-, e tenha ocorrido à formulação e à execução da Política Nacional de 
Assistência Social (PNAS) de 2004, que expressa às tensões entre os projetos em disputa nessa área e que trouxe assim as bases conceituais e organizacionais do Sistema Único de Assistência Social (SUAS), o governo desse presidente e posteriormente da Dilma, ao aderirem o neoliberalismo por meio do socialliberalismo7, impuseram limites à PNAS/SUAS e à seguridade social, pois centralizaram as ações em programas governamentais de transferência direta de renda condicionada, como o Bolsa Família, que transformaram o SUAS em um sistema de mínimo sociais, ao mesmo tempo em que demonstravam a concepção do governo da assistência social como a principal política de proteção social ${ }^{8}$.

Michel Temer, que iniciou seu governo golpista após a aprovação em 2016 do impeachment da presidente Dilma, sem a devida comprovação de crime de responsabilidade fiscal, optou pela ortodoxia neoliberal, que tem reforçado a seu favor, o que existe de mais tradicional na área da assistência social. Assim, constatase que algumas conquistas possibilitadas com o advento da PNAS/SUAS estão sendo descontruídas, pois o governo tem reforçado a condição de ajuda da assistência social, por meio do retorno do primeiro-damismo; da descoordenação das ações; do descumprimento do comando único; dos critérios ainda mais rígidos de seleção e acompanhamento dos usuários; do aprofundamento da precarização das condições e relações de trabalho; do incentivo ao trabalho de visitadores sociais vinculados ao Programa Criança Feliz, de voluntários; da promoção da caridade e da filantropia; da redução drástica do orçamento para 2018 etc. Nota-se desse modo o aprofundamento dos traços mais conservadores no padrão híbrido de gestão do SUAS, embora as forças progressistas estejam na luta pela efetivação do projeto de assistência como direito social e dever do Estado.

\footnotetext{
7 De acordo com Castelo (2012), diante dos primeiros sinais do desgaste do neoliberalismo "[...] as classes dominantes readequaram o seu projeto de supremacia, incorporando uma agenda de intervenção focalizada nas expressões mais explosivas da 'questão social', naquilo que se convencionou chamar de social-liberalismo [...]: o governo Lula é o caso mais emblemático dessa adesão ao projeto de supremacia burguesa" (CASTELO, 2012, p. 624).

8 Neste sentido, Mota (2008) aponta que "[...] enquanto avançam a mercantilização e privatização das políticas de saúde e previdência, restringido o acesso e os benefícios que lhes são próprios, a assistência social se amplia, na condição de política não contributiva, transformando-se num novo fetiche de enfrentamento à desigualdade social, na medida em que se transforma no principal mecanismo de proteção social no Brasil" (MOTA, 2008, p. 133-134).
} 


\section{O PADRÃO HÍBRIDO DE GESTÃO DO SUAS}

A formulação e a execução da PNAS/SUAS expressam as contradições entre os sujeitos que defendem projetos antagônicos de assistência social, assim como a Lei de $n^{\circ}$ 12.435, de 6 julho de 2011 (conhecida como "Lei do SUAS") e outros instrumentos políticojurídicos, como as normas operacionais e as resoluções do CNAS. Portanto, determinados avanços relacionados à criação dessa política social e à regulamentação e à construção deste Sistema, que conservam os princípios e diretrizes da LOAS (BRASIL, 1993), não anulam a convivência tensa entre formas distintas de conceber a assistência, a gestão da política social, a descentralização, a relação público e privado, os usuários e até a sociedade capitalista produtora das expressões da "questão social".

Em relação à primazia do Estado, essa diretriz não significa e também não tem resultado numa laicização e estatização dessa política social e do SUAS. A maioria das instituições de assistência social ainda hoje é de natureza privada e não promoveram, por condições econômicas e/ou ideo-políticas, reformas pautadas na perspectiva da assistência social como direito. Por outro lado, o controle social democrático e o sistema nacional de avaliação e monitoramento direcionados também a essas entidades são muito incipientes, como também os mecanismos governamentais direcionados a articulação delas em rede. Assim, pode-se afirmar que tais entidades exercem uma ampla autonomia e não constituem em uma rede socioassistencial articulada e compromissada com a política pública de assistência social9. Por se desenvolvem a margem do SUAS, o Estado tem pouco atuado como coordenador do processo de articulação e integração deste Sistema e por isso não tem sido capaz de fazer com que essas entidades transitassem do campo da ajuda para o do direito socioassistencial. A própria lógica de transferir recursos a essas entidades, sem que ocorra, nos termos de Boschetti (2006), a chamada "colaboração vigiada", demonstra que o padrão de gestão do SUAS nega, mas convive com o tradicionalismo, que se reedita com o processo de refilantropização dessa política social.

9 Raichelis (2010, p. 765-766) aponta que “[...] muitas dessas entidades não realizaram ainda o reordenamento institucional exigido pelo SUAS, inclusive em relação ao quadro de profissionais e condições de trabalho, resistindo ainda aos mecanismos de controle social e público". 
A respeito da diretriz da descentralização, nota-se que no âmbito das relações intergovernamentais a delegação de funções de gestão de programas e serviços socioassistenciais nacionais tem sido utilizada como a principal estratégia, o que demonstra uma falta de autonomia dos estados e principalmente dos municípios e uma evidente centralização das decisões e dos recursos financeiros no governo nacional. Embora identifique que os estados e municípios tenham criado alguns projetos, programas e benefícios, as principais iniciativas implementadas por esses governos foram e são elaboradas pelos ministérios e órgãos federais. De um modo geral, percebe-se uma ausência quase por completa dos estados no SUAS, pois suas atividades quando implementadas acabam assumindo um caráter de excepcionalidade, seja com suas capacitações, seja com a prestação de serviços especializados de assistência social. Em muitos municípios, nem com essas atividades ele se faz presente. Assim, para compensar a ausência do governo estadual, alguns municípios pequenos vêm se dirigindo aos de médio ou grande porte e mais diretamente ao governo federal (SILVA, 2014).

Particularmente, cabe mencionar que a transferência de recursos financeiros do governo federal para os estados e municípios por meio de instrumentos políticos-financeiros rígidos, como o Índice de Gestão Descentralizada do SUAS (IGDSUAS), demonstra que -, por mais que a União considere que o IGDSUAS seja um mecanismo indutor do alcance das metas pactuadas nacionalmente para o aperfeiçoamento da gestão do SUAS e da qualidade dos seus serviços prestados aos usuários -, ele na verdade traduz-se num instrumento que opera sob uma lógica hierarquizada, que centraliza e transfere recursos, a partir do cumprimento de metas, a um conjunto de ações implementadas pelos estados e municípios, como os programas e benefícios nacionais de transferência direta de renda condicionada. Assim, a gestão do SUAS vem valorizando os comandos mais hierarquizados, a produtividade, a quantidade e negando as relações mais compartilhadas, cooperativas e a qualidade do trabalho.

[...] os trabalhadores do SUAS, nos espaços dos CRAS, como de resto em outros âmbitos da gestão pública, estão submetidos às marcas do saber burocrático, 
que valoriza a quantificação, os comandos hierarquizados, os procedimentos e rotinas voltados ao cumprimento de prazos (geralmente estreitos) e requisitos de produtividade, nem sempre compatíveis com processos de elaboração e reflexão coletivas no ambiente institucional (YAZBEK et al, 2010, p. 199)..

Aqui cabe fazer alguns apontamentos sobre as chamadas tecnologias de gestão. A PNAS (BRASIL, 2004) incorporou a informação, o monitoramento e avaliação como um dos eixos estruturantes do SUAS. Assim, esta política social propõe a construção de duas tecnologias integradas que envolvam as três esferas de governo e a sociedade civil: um sistema de informação e outro de avaliação e monitoramento. Embora a criação desses sistemas não seja algo desprezível, pois a área é historicamente marcada pela centralização do poder e das informações e só recentemente incluiu a avaliação na sua agenda; tais tecnologias não têm um poder em si mesmo, dependendo, portanto, de valores ético-políticos que guiam esses sistemas, de condições estruturais e técnico-administrativas, e em particular de relações intergovernamentais mais horizontais.

Em muitos municípios são inexistentes as condições para a instalação e/ou o adequado uso dessas tecnologias de gestão nos equipamentos do SUAS: faltam computadores, linhas telefônicas, internet, profissionais para manusearem os sistemas, capacitação técnica etc. Naqueles que os sistemas foram implantados as dificuldades não são muito diferentes. Nota-se que nessas localidades a precarização das condições de trabalho também limitam o uso dessas tecnologias ${ }^{10}$, que vêm intensificando os processos de trabalho, burocratizando os atendimentos ${ }^{11} \mathrm{e}$ servindo como meio de avaliação de desempenho e de controle, principalmente por parte do governo federal.

10 Segundo Araújo et al. (2010, p. 115), “[...] apesar das novas tecnologias de informação e de comunicação [...] em alguns municípios são registradas dificuldades estruturais decorrentes da pobreza extrema que obstaculizam o acesso e a utilização dessas informações: a ausência de equipamentos, rede elétrica e telefônica deficiência, além da baixa qualificação dos próprios funcionários que são os operadores do sistema".

11 Silva (2013, p. 315) constatou que os "[...] limites dificultam um acompanhamento substantivo dessas famílias. Em suas palavras, pôde-se identificar que acorre um acompanhamento de cadastros e não de famílias". 
No âmbito das relações entre Estado e sociedade civil, identificase em quase todas as esferas governamentais a existência de conselhos e a regularidade na realização de conferências, que são instâncias deliberativas do sistema descentralizado e participativo da política de assistência social. Entretanto, a criação desses espaços importantes para controlar e avaliar esta política social é insuficiente para assegurar a descentralização política, que depende também da ampliação da participação social, da publicização das informações, da representação dos interesses como públicos, da igualdade de condições nos processos de discussões e decisões, do caráter deliberativo e da relação com o Poder Executivo e Legislativo, quanto à legitimidade de tais espaços e à aprovação e cumprimento das medidas por eles deliberadas.

As críticas realizadas pelas forças (neo)conservadoras quanto ao caráter deliberativo de tais conselhos acabam sendo mais um dos agravantes e são coerentes com as determinações do Banco Mundial quanto à criação dos mecanismos de consulta ${ }^{12}$. Neste sentido, a defesa dos conselhos enquanto espaços consultivos/ de interlocução limita a participação nessa área, que ainda hoje, mesmo com importantes campanhas e mobilizações sociais, é marcada por uma participação incipiente dos usuários, que estão sendo sub-representados, quase sempre, pelas entidades de assistência social e organizações dos trabalhadores; por entidades de assistência social que não têm ultrapassado uma participação corporativista, que tradicionalmente se articula de maneira estreita à participação assistencialista; e pela indicação de representantes da sociedade civil pelos governos: esses em muitos estados e municípios permanecem por longos períodos na presidência desses conselhos e pouco investem na capacitação dos conselheiros e nas estruturas desses espaços. Por essa razão, concorda-se com Araújo et al. (2010, p. 132), que "[...] o conflito de projetos, embora comum a todos os outros grupos envolvidos na implementação da Política, é mais visível, justamente no âmbito dos conselhos".

12 Não por acaso, o ex-chefe do antigo Ministério do Desenvolvimento Social e Combate à Fome (MDS), Patrus Ananias de Sousa, propõe em 2007 que os conselhos deliberativos como o CNAS assumissem o caráter consultivo. "Penso que devemos defender os conselhos e seus respectivos espaços de discussão como importantes agentes de interlocução do Estado com a sociedade [...]. Em que pese toda força mobilizadora, eles não podem ter caráter deliberativo e devem se constituir como um fórum que deve ser, como vem sendo, considerado pelo governo" (SOUSA, 2007, p. 1). 
Na gestão do trabalho do SUAS ${ }^{13}$ também se constata a disputa entre projetos de assistência social distintos e que imprime alguns dos principais traços do padrão híbrido de gestão deste Sistema. Pode-se apontar que ainda hoje a gestão do órgão responsável pela assistência social em muitos estados e municípios é indicada pelo governante à primeira-dama ou a um político da coalizão partidária, o que induz o clientelismo. Embora as esposas desses governantes busquem hoje uma formação universitária (o que tem sido chamado de primeiro-damismo reciclado), isso não elimina a ideia de um Estado ainda como uma extensão das relações familiares. Ao serem financiadas pelos fundos de assistência social, algumas instituições caritativas/filantrópicas dirigidas por determinados governantes locais ou suas esposas, vêm implementado ações paralelas ao SUAS e/ou utilizando tais recursos para contratação de trabalhadores, que atuam nos órgãos governamentais responsáveis pela gestão deste Sistema ${ }^{14}$. Assim, a terceirização da força de trabalho (hoje em larga escala com o processo de intensificação da precarização das relações de trabalho) vem alimentando a patronagem e as práticas de favor, mesmo com a criação da Norma Operacional Básica de Recursos Humanos do SUAS (NOB-RH/SUAS) em 2006 (BRASIL, 2006) e a realização de alguns concursos públicos em alguns estados e municípios com o número de vagas reduzido e aquém das necessidades institucionais e sociais.

Entretanto, cabe aqui afirmar que as condições e relações de trabalho no âmbito do SUAS não está ligada apenas a um problema de gestão, mas passam fundamentalmente, segundo Raichelis (2010, p. 763), pelos “[...] modos de organização do trabalho na sociedade capitalista contemporânea, e das condições concretas em que se realiza, particularmente nas políticas sociais, que,

13 De acordo com o Ministério do Desenvolvimento Social (BRASIL, [2017]), a gestão do trabalho no SUAS corresponde a uma dimensão /área da gestão deste Sistema, que trata das questões referentes ao trabalho e aos profissionais e técnicos que atuam nesta política social.

14 Segundo Yazbek et al. (2010, p. 144), “[...] vários depoimentos colhidos evidenciaram a presença das primeiras damas na condução da política de assistência social, mas acompanhada agora de um discurso legitimador dessa presença, em função de um movimento das esposas de governantes em busca de uma formação acadêmica [...] é o que poderíamos denominar de primeiro-damismo reciclado". Couto et al (2010, p. 213) também apontam que as "instituições filantrópicas, além de encontrarem-se sob o comando e gestão das primeiras-damas, são financiadas pelo Fundo Municipal de Assistência Social, destacando-se que entre as ações desenvolvidas, são responsáveis em alguns municípios do Parará e do Rio Grande do Sul, pela contratação de recursos humanos disponibilizados posteriormente ao órgão gestor da Assistência Social". 
como a assistência social, tiveram um grande crescimento nesses últimos anos".

\section{CONSIDERAÇÕES FINAIS}

Nessa direção, este trabalho -, ao procurar analisar a construção da política de assistência social à luz dos projetos coletivos em disputa nessa área e assim demonstrar a constituição de um padrão híbrido de gestão do seu sistema descentralizado e participativo, hoje denominado de SUAS -, considera que uma transformação realista da gestão deste Sistema, que negue em termos prático o tradicionalismo e o gerencialismo (que reproduz o patrimonialismo, a lógica do favor etc. a partir de uma nova institucionalidade), depende também de uma transformação da sociedade e do próprio Estado. Em outras palavras, a construção de uma gestão pública e democrática do SUAS está associada à transformação da sua cultura política, que passa pela recuperação no sentido gramsciano da "grande política". Esta envolve um processo contra hegemônico, que depende da necessidade e possibilidade das classes subalternas colocarem em prática o projeto de democratização, que fundamenta o projeto de assistência como direito social e dever do Estado. Assim, considerase que importantes mediações podem auxiliar na construção do consenso na sociedade, como forma de transformar o Estado e ordem burguesa. É claro que uma transformação realista desta ordem social depende também, como aponta Mészáros (2010), do envolvimento das forças organizadas do trabalho, que conscientemente neguem as determinações estruturais da reprodução material estabelecida.

\section{REFERÊNCIAS}

ANTUNES, R. A desertificação neoliberal no Brasil (Collor, FHC e Lula). Campinas, SP: Autores Associados, 2005.

ARAÚJO, C. C. et al. Implantação e implementação do sistema único de assistência social (Suas) nos estados do Pará. Maranhão e Pernambuco: uma análise dos resultados de pesquisa empírica. In: COUTO, B. R.; YAZBEK, M. C.; SILVA e SILVA, M. O; RAICHELIS, R. (Orgs.). O sistema único de assistência social no Brasil: uma realidade em movimento. São Paulo: Cortez, 2010. 
BEHRING, E. R.; BOSCHETTI, I. Política social: fundamentos e história. São Paulo: Cortez, 2006.

BENTO, L. V. Governança e governabilidade na reforma do Estado: entre eficiência e democratização. São Paulo: Manole, 2003.

BOSCHETTI, I. A relação Estado/mercado no processo de constituição da assistência social no Brasil durante o governo Collor. Serviço Social e Sociedade, São Paulo, n. 43, 1993.

BOSCHETTI, I. Seguridade social e trabalho: paradoxos na construção das políticas de previdência e assistência social no Brasil. Brasília: Letras Livres; UnB, 2006.

BRASIL. Ministério do Desenvolvimento Social. Gestão do trabalho. Disponível em: <http://mds.gov.br/assuntos/assistenciasocial/gestao-do-suas/gestao-do-trabalho-1> . Acesso: 16 mar. 2016.

BRASIL. Presidência da República. Lei de $n^{\circ}$ 12.435, de 6 de julho de 2011. Altera a Lei no 8.742, de 7/12/1993, que dispõe sobre a organização da Assistência Social. Disponível em: <http://www. planalto.gov.br/ccivil_03/_ato2011-2014/2011/lei/l12435.htm>. Acesso em: 17 ago. 2017.

BRASIL. Presidência da República. Lei n 8.742, de 7 dezembro de 1993. Dispõe sobre a organização da Assistência Social e dá outras providências. Disponível em: <http://www.planalto.gov.br/ ccivil_03/leis/L8742.htm>. Acesso em: 17 ago. 2017.

BRASIL. Presidência da República. Medida Provisória n 813 , de 1 janeiro de 1995. Dispõe sobre a organização da Presidência da República e dos Ministérios, e dá outras providências. Disponível em: <http://www2.camara.leg.br/legin/fed/medpro/1995/ medidaprovisoria-813-1-janeiro-1995-377320-publicacaooriginal-1pe.html>. Acesso em: 17 ago. 2017.

BRASIL. Secretaria Nacional de Assistência Social. Sistema Único de Assistência Social (SUAS): Norma Operacional Básica: Recursos Humanos (NOB/RH)/SUAS. Brasília (DF), 2006.

BRASIL. Secretaria Nacional de Assistência Social. Política Nacional de Assistência Social. Brasília (DF), 2004. 
BRASIL. Presidência de República. Decreto-lei n² 200, de 25 fevereiro de 1967. Dispõe sobre a organização da administração federal, estabelece diretrizes para a reforma administrativa e dá outras providencias. Brasília (DF), 1967. Disponível em: <http:// www.planalto.gov.br/ccivil_03/decreto-lei/Del0200.htm>. Acesso: 17 ago. 2017.

BRAVO, M. I. S. A política de saúde no Brasil: trajetória histórica. In: CAPACITAÇÃO para conselheiros de saúde: textos de apoio. Rio de Janeiro: UERJ/DEPEXT/NAPE, 2001.

CASTELO, R. O novo desenvolvimentismo e a decadência ideológica do pensamento econômico brasileiro. Serviço Social e Sociedade, São Paulo, n. 112, p. 613-636, out./dez. 2012.

COLLOR, F. Brasil: um projeto de reconstrução nacional. Brasília (DF): Senado Federal, 2008.

CONSELHO NACIONAL DE ASSISTÊNCIA SOCIAL. Ata da 037 reunião ordinária. Brasília (DF), 1997.

COUTINHO, C. N. Contra a corrente: ensaios sobre democracia e socialismo. São Paulo: Cortez, 2008.

COUTO, B. R. et al. A implantação e implementação do Suas no Paraná e no Rio Grande do Sul: um movimento em processo. In: COUTO, B. R. et al. (Orgs.). O sistema único de assistência social no Brasil: uma realidade em movimento. São Paulo: Cortez, 2010.

DECLARAÇÃo do Rio de Janeiro: frente social dos estados e municípios. In: SPOSATI, A. (Coord.). Carta-tema: a assistência social no Brasil, 1883-1990. São Paulo: Cortez, 1991.

FERNANDES, F. A transição prolongada: o período pósconstitucional. São Paulo: Cortez, 1990.

FLEURY, S. Assistência na previdência social: uma política marginal. In: SPOSATI, A.; FALCÃO, M. do C.; FLEURY, S. Os direitos (dos desassistidos) sociais. São Paulo, 1999.

HARVEY, D. O neoliberalismo: história e implicações. São Paulo: Loyola, 2008.

IAMAMOTO, M. V. Os espaços sócio-ocupacionais do assistente social. In: SERVIÇO social: direitos sociais e competências 
profissionais. Brasília (DF): CFESS/ABEPSS, 2009.

IASI, M. L. O Estado depois do ajuste: políticas sociais na época da hipocrisia deliberada. In: PASTORINI, A. et al. Estado e cidadania: reflexões sobre as políticas públicas no Brasil contemporâneo. RJ: Editora FGV, 2012.

MÉSZÁROS, I. Atualidade histórica da ofensiva socialista: uma alternativa radical ao sistema parlamentar. São Paulo: Boitempo, 2010.

MOTA, A. A centralidade da assistência social na seguridade social brasileira nos anos 2000. In: MOTA, A. E. (Org.). O mito da assistência social: ensaios sobre Estado, política e sociedade. São Paulo: Cortez, 2008.

MOTA, A. E. Cultura da crise e seguridade social: um estudo sobre as tendências da previdência e da assistência social brasileira nos anos 80 e 90. SP: Cortez, 2000.

NETTO, J. P. Capitalismo monopolista e serviço social. São Paulo: Cortez, 2001.

NETTO, J. P. A construção do projeto ético-político do Serviço Social. In: MOTA, A. E. et al. (Orgs). Serviço Social e saúde: formação e trabalho profissional. São Paulo: OPAS; OMS; Ministério da Saúde, 2006.

PASTORINI, A. O círculo "maldito" da pobreza no Brasil: a mistificação das "novas" políticas sociais. 2002. Tese (Doutorado em Serviço Social) Escola de Serviço Social, Universidade Federal do Rio de Janeiro, Rio de Janeiro, 2002.

PEREIRA, P. A. P. Reflexões sobre a medida provisória $n^{\circ} 813$, de 01/01/95. Serviço Social e Sociedade, São Paulo, n. 47, p. 147-150, abril de 1995 .

RAICHELIS, R. Intervenção profissional do assistente social e as condições de trabalho no Suas. Serviço Social e Sociedade, São Paulo, n. 104, p. 750-772, out./dez. 2010.

DECLARAÇÃO do Rio de Janeiro: frente social dos estados e municípios. In: SPOSATI, A. (Coord.). Carta-tema: a assistência social no Brasil, 1883-1990. São Paulo: Cortez, 1991. 
SILVA, R. R. da. (Des)centralização, contrarreforma do Estado e política de assistência social no Brasil. 2014. Tese (Doutorado em Serviço Social)-Escola de Serviço Social, Universidade Federal do Rio de Janeiro, Rio de Janeiro, 2014.

SILVA, R. R. da. "Reforma" da política de assistência social no município do Rio de Janeiro: em questão a análise da atuação dos CRASs e CREASs. O social em questão, Rio de Janeiro, ano 17, n. 30, 2013.

SOARES, L. T. R. Ajuste neoliberal e desajuste social na América Latina. Petrópolis: Vozes, 2001.

SOUSA, P. A. de. Ver as árvores e enxergar o bosque. Jornal Valor Econômico, São Paulo, 10 ago. 2007. Opinião.

SOUZA FILHO, R. de. Gestão pública e democracia: a burocracia em questão. Rio de Janeiro: Lumen Juris, 2011.

SPOSATI, A. (Coord.). Carta-tema: a assistência social no Brasil: 1983-1990. São Paulo: Cortez, 1991.

TEIXEIRA, A. M. de P. Previdência social no Brasil: da revolução passiva à contra-reforma. 2006. Tese (Doutorado em Serviço Social)-Escola de Serviço Social, Universidade Federal do Rio de Janeiro, Rio de Janeiro, 2006.

TEIXEIRA, J.; BRAZ, M. O projeto ético-político do Serviço Social. In: SERVIÇO social: direitos sociais e competências profissionais. Brasília (DF): CFESS; ABEPSS, 2009.

TELLES, V. da S. Direitos sociais: afinal do que se trata? Revista USP, São Paulo, n. 37, mar./maio 1998.

YAZBEK, M. C. et al. O sistema único de assistência social em São Paulo e Minas Gerais: desafios e perspectivas de uma realidade em movimento. In: COUTO, B. R. et al. (Orgs.). O sistema único de assistência social no Brasil: uma realidade em movimento. São Paulo: Cortez, 2010. 